UDC 332.187.62:332.1

Submitted: 16.12 .2018

LBC 65.9(2Poc)-56

Accepted: 31.01 .2019

\title{
THE TRENDS AND PROSPECTS OF LEASING DEVELOPMENT AS A RELEVANT FINANCIAL TOOL OF INVESTMENTS IN THE SOUTHERN REGIONS OF RUSSIA
}

\author{
Emma V. Kuzmina \\ Volgograd State University, Volgograd, Russian Federation \\ Elina S. Kuzmina \\ Volgograd State University, Volgograd, Russian Federation
}

\begin{abstract}
Leasing owing to the unique economic essence is considered to be a booster for economic, innovation and investment business activity of any level. In the conditions of competition, economic subjects are constantly in search of innovative approaches to business operations and effective distribution of financial resources. This determines the demand for leasing as an efficient way to make investments into business.

The relevance of the research regarding prospects of leasing development at the regional level does not raise doubts as the issue of sources of new investments into the real sector of Russian economy is particularly urgent today. Consequently, one of the ways to solve this issue is to apply new financial instruments of production, investment leasing in particular. In modern Russian economy the real investments can be raised by means of leasing which are quite necessary for modernization of fixed assets in various branches, including those in the most vulnerable links of the Russian economy.

This paper presents the results of analyzing a tendency and features of leasing market development on the national and regional levels. The authors have given an assessment of investment climate in the Southern regions and systemized the factors on the basis of which both the general risks and the specific regional risks are marked out.

As a result of assessing the experience of leasing functioning, some regional features have been revealed, drivers and development prospects of the leasing mechanism in the southern regions hev been defined. Furthermore, the positive approaches which should be put into practice have been revealed. Some points of growth ahave been defined in various segments of business based on the influencing support factors. As examples of growth drivers we can consider auto leasing, leasing of agricultural machinery, operating leasing, leasing for individuals and a financial supermarket.

On the basis of generalization of possible ways that we can use to develop the regional leasing market there are directions to improve the realization of leasing mechanism on the regional level which can be used in practice.

Key words: leasing market, leasing, investments, potential, risks, Southern regions.
\end{abstract}

Citation. Kuzmina E.V., Kuzmina E.S. The Trends and Prospects of Leasing Development as a Relevant Financial Tool of Investments in the Southern Regions of Russia. Vestnik Volgogradskogo gosudarstvennogo universiteta. Seriya 3, Ekonomika. Ekologiya [Science Journal of Volgograd State University. Global Economic จे System], 2019, vol. 21, no. 1, pp. 56-65. (in Russian). DOI: https://doi.org/10.15688/jvolsu3.2019.1.5

УДК 332.187.62:332.1

Дата поступления статьи: 16.12.2018

ББК $65.9(2 \mathrm{Poc})-56$

Дата принятия статьи: 31.01.2019

\section{ТЕНДЕНЦИИ И ПЕРСПЕКТИВЫ РАЗВИТИЯ ЛИЗИНГА КАК АКТУАЛЬНОГО ФИНАНСОВОГО ИНСТРУМЕНТА ИНВЕСТИЦИЙ В ЮЖНЫХ РЕГИОНАХ РОССИИ}

\author{
Эмма Вячеславовна Кузьмина \\ Волгоградский государственный университет, г. Волгоград, Российская Федерация
}

Вестник ВолГУ. Серия 3, Экономика. Экология. 2019. Т. 21. № 1 


\section{Элина Сергеевна Кузьмина}

Волгоградский государственный университет, г. Волгоград, Российская Федерация

Аннотация. Лизинг в силу своей уникальной экономической сущности является стимулятором экономической, инвестиционной и инновационной активности бизнеса любого уровня. В условиях конкуренции экономические субъекты постоянно находятся в поисках инновационных подходов к ведению и развитию бизнеса и стремятся оптимизировать процесс распределения финансовых ресурсов, что и определяет востребованность лизинга как эффективного формата инвестиций в бизнес.

Актуальность исследования перспектив развития лизингового рынка на региональном уровне не вызывает сомнения, поскольку вопрос источников поступлений новых инвестиций в реальный сектор российской экономики на сегодняшний день стоит достаточно остро и одним из вариантов выхода из создавшегося положения является широкое применение новых финансовых инструментов производственного инвестирования, к которым относится лизинг. В современной экономике России с помощью лизинга могут быть привлечены реальные инвестиции, необходимые для модернизации основных фондов в различных отраслях и в том числе в наиболее уязвимых звеньях российской экономики.

В работе представлены результаты анализа тенденции и особенностей развития лизингового рынка на общенациональном и региональном уровнях. Авторами дана оценка инвестиционного климата южных регионов и систематизация влияющих на него факторов, на основе которых выделены как общие для лизингового рынка риски, так и специфические, характерные для регионов.

В результате оценки опыта функционирования лизинга выявлены региональные особенности, определены драйверы и перспективы развития лизингового механизма в южных регионах, а также выделены позитивные подходы, которые следует применить на практике. Точки роста определены в различных сегментах бизнеса с привязкой к влияющим факторам поддержки. В качестве примеров драйверов роста показаны автолизинг, лизинг сельскохозяйственной техники, оперативный лизинг, лизинг для физических лиц и финансовый супермаркет.

На основе обобщения возможных путей развития регионального лизингового рынка определены направления совершенствования реализации механизма лизинга на региональном уровне, которые могут найти применение на практике.

Ключевые слова: лизинговый рынок, лизинг, инвестиции, потенциал, риски, южные регионы.

Цитирование. Кузьмина Э. В., Кузьмина Э. С. Тенденции и перспективы развития лизинга как актуального финансового инструмента инвестиций в южных регионах России // Вестник Волгоградского государственного университета. Серия 3, Экономика. Экология. - 2019. - T. 21, № 1. - C. 56-65. - DOI: https://doi.org/ 10.15688/jvolsu3.2019.1.5

Современные экономические условия отличаются высоким уровнем риска и неопределенности, вызванным глобализацией рынков, усложнением технологических систем во всех сферах, усилением конкуренции, ростом социальной и финансовой напряженности. Все это предопределяет необходимость внедрения новых инновационных способов обновления и совершенствования основных средств в различных отраслях деятельности. Одним из востребованных инструментов становится лизинг, объединяющий элементы внешнеторговых, кредитных и инвестиционных операций.

Преимущества лизингового механизма, такие как налоговые льготы, возможность своевременного обеспечения производства основными средствами, гибкость графиков платежей, простота учета, меры государственной поддержки, позволили лизинговым сделкам завоевать лидирующие позиции среди инвестиционных продуктов в мировой экономике. Опыт развивающихся стран (Китай, Малайзия, Корея) показал, что благодаря лизинговым схемам стало возможным в сжатые сроки осуществить техническое перевооружение и модернизацию национальных хозяйств этих государств [1].

В современной экономике России с помощью лизинга могут быть привлечены реальные инвестиции, необходимые для модернизации основных фондов в различных отраслях и регионах, в том числе в наиболее уязвимых звеньях российской экономики.

Проблема привлечения инвестиционных ресурсов в реальный сектор экономики отдельных российских регионов на сегодняшний день стоит достаточно остро. Одним из вариантов выхода из создавшегося положения 
является широкое применение новых финансовых инструментов производственного инвестирования, к которым относится лизинг. Данный факт предопределяет актуальность исследования проблем и перспектив развития российского лизингового рынка на общенациональном и региональном уровнях.

Вопросы теории и практики лизинговых отношений нашли отражение в работах как российских, так и зарубежных ученых. Однако особенности функционирования современного лизингового рынка, существующие проблемы и возникающие риски, а также необходимость развития лизинга как актуального финансового инструмента в современных условиях требуют более глубоких исследований.

Опыт развития экономики последних десятилетий показал, что в решении проблем финансирования крупномасштабных инвестиционных проектов эффективность лизинга достаточно высока. При реализации крупномасштабных финансовых проектов многообразие форм лизинговых операций и значительные финансовые возможности крупных западных лизинговых компаний и их учредителей позволяют рационально распределять не только денежные средства, но и риски, и ответственность. На практике достаточно часто традиционные методы, которые обычно предприниматели применяют в торговле и кредитно-банковской деятельности, оказываются менее эффективными.

Финансовый лизинг, получивший широкое распространение за рубежом как эффективная форма инвестиционной деятельности, по ряду объективных причин становится все более актуальным и необходимым инструментом в России. В ведущих странах мира объем лизинговых операций каждый год увеличивается в среднем на 10-12\% [1]. В странах с развитым лизинговым рынком доля лизинга в общем объеме инвестиций в основной капитал составляет 15-30\%, в России данный показатель в 2014 г. составил 7,2\% [2], что свидетельствует о наличии значительного потенциала в развитии лизинга в России в долгосрочной перспективе. Это подтверждается и положительной динамикой изменения доли лизинга в ВВП с 0,9 \% в 2016 г. до 1,2 \% за 2017 год [4].
Лизинговый рынок можно рассматривать как производную экономического роста, остальные социально-экономические факторы определяют образ или конфигурацию лизинга в стране. Динамика ВВП позволяет отслеживать общее состояние инвестиционной активности и состояние бизнеса, в том числе финансового рынка и рынка долгосрочной аренды.

По итогам 2017 г. объем новых сделок лизингового рынка составил 1095 млрд руб. и увеличился на 47,6 \% по сравнению с 2016 г., при этом был превышен исторический максимум по данному показателю. Сумма новых договоров лизинга за 2017 г. выросла на 40,9 \% по сравнению с 2016 г. и составила около 1620 млрд рублей [4]. Основными факторами активного роста рынка стали: снижение ключевой ставки ЦБ РФ, субсидии и программы государственной поддержки отдельных видов лизинга. При этом госпрограммы льготного лизинга обеспечили поддержку, прежде всего, транспортным сегментам.

В территориальном распределении нового бизнеса за 2017 г. доля Москвы выросла с $31,2 \%$ до 41,7 \% вследствие наращивания в столице сделок с железнодорожной и авиатехникой. На этом фоне доля пяти федеральных округов России показала снижение, однако в абсолютных величинах объем новых сделок во всех федеральных округах показал рост за данный период. Отдельно стоит отметить Южный Федеральный округ (далее ЮФО), доля которого выросла с 4,8 \% по итогам 2016 г. до 5,9 \% за 2017 год [4].

По мнению агентства РА Эксперт, рост лизингового бизнеса в ЮФО связан в определенной степени и с инфраструктурными проектами в Крыму, где износ основных фондов за 2016 г. составил 51,7 \%, что выше среднероссийского уровня $-47,5 \%$. В ходе анкетирования ряда лизинговых компаний отмечен повышенный спрос в регионах на автотранспорт и спецтехнику. Доля Северо-Кавказского Федерального округа (далее СКФО) в лизинговом рынке самая низкая и составила только 0,9 \%, что подтверждает высокие риски развития лизингового рынка в данном регионе.

Оценка структуры лизингового рынка по количеству лизинговых компаний в регионах показывает, что ситуация здесь принципиаль- 
но отличается: доля СКФО составляет $4,1 \%$, а ЮФО - 10,2 \%, то есть лизинговые компании в регионах достаточно представлены, но объем их бизнеса незначителен по сравнению с объемом новых сделок в Москве.

Анализ тенденций развития лизингового рынка в южных регионах целесообразно начать с оценки инвестиционной привлекательности и тенденций развития самих регионов. В настоящее время ЮФО включает Астраханскую, Волгоградскую и Ростовскую области, республики Калмыкия, Адыгея, Крым, Краснодарский край, город Севастополь. СКФО включает Ставропольский край, Чеченскую, Карачаево-Черкесскую и КабардиноБалкарскую республики, республики Дагестан, Ингушетия, Северная Осетия.

Рейтинг инвестиционной привлекательности регионов России в 2017 г. впервые за длительное время показал снижение интегрального инвестиционного риска и всех его составляющих, при этом наибольшее снижение наблюдалось у финансового риска $(-4,8 \%)$, при этом в целом наблюдается рост потенциала [3]. Рейтинг инвестиционного климата по южным регионам России в 2017 г., основанный на интегральной оценке составляющих инвестиционного потенциала и риска, отражен в таблице 1 .

Инвестиционный климат в регионах и общие тенденции экономического развития и развития финансового рынка предопределяют и реализацию лизинговых схем в регионах. Как видно из таблицы 1 , для большинства республик Северного Кавказа характерен высокий риск и не сильно высокий потенциал, что предопределяет тот факт, что многие кредитные, лизинговые и страховые организации не ведут свою деятельность в данных регионах.
Рассматривая развитие ЮФО, необходимо отметить, что регион имеет выгодное транспортно-географическое положение, обусловленное связью с другими регионами РФ и странами Средней, Юго-Западной и Южной Азии, наиболее благоприятные условия для проживания, отдыха, развития сельского хозяйства, а также оптимальный природно-ресурсный потенциал. Макрорегион играет значительную роль в обеспечении продовольственной безопасности страны. Здесь находится шестая часть всех посевных площадей, на которой выращивается более $25 \%$ общего российского объема зерновых культур, 50 \% подсолнечных семян и $20 \%$ овощей [6].

Также ЮФО богат топливно-энергетическими и минерально-сырьевыми ресурсами. Транспортная инфраструктура региона обеспечивает логистические потоки по международному транспортному коридору Север-Юг и Транссибирской железнодорожной магистрали, а также и экспортно-импортные перевозки грузов в бассейнах Азовского, Черного и Каспийского морей. ЮФО занимает шестое место среди федеральных округов РФ по объему инвестиций в основной капитал.

Оценивая изменение инвестиционного климата в южных регионах необходимо отметить несколько существенных факторов:

1. Ослабление влияния агропромышленного комплекса (АПК) после очевидного эффекта, вызванного девальвацией. Неблагоприятная мировая ценовая конъюнктура на сельскохозяйственную продукцию привела к снижению экспорта и, соответственно, падению инвестиционной привлекательности ряда мощных зерновых регионов страны с 2016 года. Это стало одной из причин пере-

Рейтинг инвестиционного климата южных регионов России в 2017 г.

\begin{tabular}{|l|l|}
\hline \multicolumn{1}{|c|}{ Регион } & \multicolumn{1}{|c|}{ Рейтинг } \\
\hline Краснодарский край & Максимальный потенциал - минимальный риск (1А) \\
\hline Ростовская область & Средний потенциал - минимальный риск (2А) \\
\hline $\begin{array}{l}\text { Астраханская область, Волгоградская область, } \\
\text { Республика Крым, Ставропольский край }\end{array}$ & Средний потенциал - умеренный риск (3В1) \\
\hline Республика Адыгея, г. Севастополь & Незначительный потенциал - умеренный риск (3В2) \\
\hline Республика Дагестан & Пониженный потенциал - высокий риск (3С1) \\
\hline $\begin{array}{l}\text { Чеченская Республика, Карачаево-Черкесия, Ка- } \\
\text { бардино-Балкария, Калмыкия, Северная Осетия }\end{array}$ & Незначительный потенциал - высокий риск (3С2) \\
\hline Республика Ингушетия & Низкий потенциал - высокий риск (3С3) \\
\hline
\end{tabular}

Примечание. Составлено по: [3]. 
мещения Краснодарского края с первой на четвертую позицию по интегральному инвестиционному рейтингу и Ставрополья с 16-й позиции на 24-ю по сравнению с 2015 годом.

Но необходимо отметить, что воздействие развития АПК должно внести существенный вклад в развитие региональной экономики. Несмотря на ценовую волатильность на мировых рынках, спрос на сельскохозяйственную продукцию растет и предопределяет необходимость инвестиций в сельскохозяйственное производство. И рейтинги аграрных регионов должны повыситься, что будет зависеть в том числе и от мер государственной поддержки агропромышленного комплекса. Среди основных инициатив в этой сфере можно отметить принятие национального проекта по развитию экспорта продукции АПК до 2020 года. К этому сроку Россия, как планируется, будет экспортировать сельскохозяйственной продукции на 21,4 млрд долларов (в 2016 г. - на 17 млрд), а еще через 5 лет - на 30 млрд [6].

2. Снижение стимулирующего воздействия крупномасштабных федеральных программ на экономику регионов. Ярким примером здесь выступают Крым и Севастополь, снижение рейтинга которых произошло из-за наблюдающихся проблем и пробелов в системе организации и управления масштабными бизнес-процессами. Это было связано с неспособностью эффективного освоения централизованных бюджетных средств и привле- чения местного бизнеса к реализации крупных проектов.

3. Смена драйверов экономического роста - усиление влияния отрасли машиностроения. Особенно явно влияние данного фактора проявилось для Ростовской области, считающейся по преимуществу аграрной. В рейтинге за 2017 г. Ростовская область, на фоне проседания по агропромышленной сфере, поднялась на 3 позиции в списке по интегральному инвестиционному риску (с 21-й на 18-ю) в первую очередь за счет машиностроительной отрасли, представленной крупнейшим производителем сельскохозяйственной техники «Ростсельмаш» и вертолетостроительным заводом «Роствертол».

Оценка объемов лизингового рынка СКФО (табл. 2) показывает, что объем нового бизнеса (стоимости лизингового имущества) по региону за 2017 г. составил 8,7 млрд руб. и вырос на $28 \%$ по сравнению с 2016 годом. Количество действующих лизинговых компаний по ЮФО увеличилось с 22 до 23, при этом появились новые крупные игроки - лизинговые компании с государственным участием, такие как «Балтийский лизинг» и «Альфа лизинг».

Концентрация сделок по топ-10 лизинговым компаниям в СКФО за 2017 г. составила $91 \%$ против $94 \%$ в 2016 году. Несмотря на снижение показателя, уровень контроля десятью лизинговыми компаниями регионального рынка достаточно высок. Наибольший объем

Динамика объема нового бизнеса в разрезе лизинговых компаний по СКФО

Таблииа 2 за 2016-2017 гг.

\begin{tabular}{|l|c|c|c|}
\hline $\begin{array}{c}\text { Наименование } \\
\text { лизинговой компании }\end{array}$ & 2016 г., млн руб. & 2017 г., млн руб. & Темп роста, \% \\
\hline Сбербанк Лизинг (ГК) & 1028,6 & 1861,6 & 181 \\
\hline ЛК Европлан & 1063,9 & 1750,7 & 165 \\
\hline ВТБ Лизинг & 548,1 & 885,0 & 161 \\
\hline КАМАЗ-ЛИЗИНГ(ГК) & 650,4 & 847,1 & 130 \\
\hline ВЭБ-лизинг & 584,9 & 631,0 & 108 \\
\hline ЮниКредит Лизинг & 128,2 & 476,0 & 371 \\
\hline Балтийский лизинг (ГК) & - & 454,0 & - \\
\hline РЕСО-Лизинг & 226,8 & 407,6 & 180 \\
\hline Элемент Лизинг & 41,2 & 405,0 & 983 \\
\hline САВСАDЕ Лизинг & 64,0 & 226,0 & 353 \\
\hline Прочие ЛК & 2469,9 & 1181,1 & 48 \\
\hline \multicolumn{1}{|c|}{ Итого } & 6806,0 & 9125,1 & 128 \\
\hline
\end{tabular}

Примечание. Составлено по: [4]. 
сделок в 2017 г. приходился на государственные компании «Сбербанк лизинг», «Европлан» и «ВТБ лизинг».

Рынок лизинга ЮФО более развит. Как видно из таблицы 3 , объем нового бизнеса за 2017 г. составил 59,2 млрд руб., что на $64 \%$ выше уровня 2016 г., при этом количество лизинговых компаний увеличилось с 53 до 59.

Концентрация сделок по топ-10 лизинговым компаниям в ЮФО за 2017 г. составила $80 \%$ против $72 \%$ в 2016 году. Связано это со значительным ростом сделок по Государственной транспортной лизинговой компании, объем нового бизнеса по которой составил 15,7 млрд руб. при росте $935 \%$ по сравнению с 2016 годом. На данную компанию в 2017 г. приходилось $27 \%$ регионального лизингового рынка. На втором месте по объему сделок в 2017 г. «Сбербанк лизинг», на третьем - ЛК «Европлан». Также на рынок вышла новая компания «Гознак-лизинг», специализирующаяся на лизинге легкового и грузового транспорта и специализированного оборудования.

Проведенная оценка позволяет сделать вывод о том, что основной вклад в развитие лизингового рынка в южных регионах внесли транспортные сегменты, сегменты строительной, сельскохозяйственной техники и обо- рудования для пищевой промышленности. Это можно проследить, сравнив объемы текущих сделок лизинговых компаний в южных регионах и рейтинги лизинговых компаний по объемам сделок с транспортом, строительной и сельскохозяйственной техникой.

Выявленные тенденции объясняются реализацией политики импортозамещения в России и значимой ролью АПК для экономики южных регионов. На федеральном уровне для поддержки приобретения сельхозтехники используют механизм прямого субсидирования производителей. На региональном уровне в 2017 г. приняли механизм субсидирования лизинговых платежей.

Кроме лизинга сельхозтехники, востребован в южных регионах и лизинг автотранспорта и спецтехники, что связано с общим подъемом авторынка, обширными программами государственного стимулирования и крупными инфраструктурными проектами на юге страны.

Многие лизинговые компании продолжают активно развивать сегменты финансирования легкового транспорта и конкурировать при этом с банковским кредитованием. Немалую поддержку лизингу, в том числе на юге России, оказывают программы субсидирова-

Динамика объема нового бизнеса в разрезе лизинговых компаний по ЮФО за 2016-2017 гг.

\begin{tabular}{|c|c|c|c|}
\hline $\begin{array}{c}\text { Наименование } \\
\text { лизинговой компании }\end{array}$ & 2016 г., млн руб. & 2017 г., млн руб. & Темп роста, \% \\
\hline $\begin{array}{l}\text { Государственная транспортная } \\
\text { лизинговая компания }\end{array}$ & 1679,5 & 15703,6 & 935 \\
\hline Сбербанк Лизинг (ГК) & 2714,6 & 6653,0 & 245 \\
\hline ЛК Европлан & 3670,3 & 5202,7 & 142 \\
\hline ВТБ Лизинг & 3454,9 & 4503,6 & 130 \\
\hline РЕСО-Лизинг & 2133,3 & 3292,5 & 154 \\
\hline Сименс Финанс & 2823,4 & 3018,1 & 107 \\
\hline ВЭБ-лизинг & 3363,6 & 2973,6 & 88 \\
\hline Балтийский лизинг (ГК) & 1070,0 & 2584,0 & 241 \\
\hline ЮниКредит Лизинг & 1336,5 & 1687,3 & 126 \\
\hline Гознак-лизинг & & 1470,0 & \\
\hline Элемент Лизинг & 1106,9 & 1408,0 & 127 \\
\hline Альфа Лизинг (ГК) & 261,8 & 972,8 & 372 \\
\hline Интерлизинг (ГК) & 607,8 & 952,6 & 157 \\
\hline CARCADE Лизинг & 412,0 & 839,3 & 204 \\
\hline ГЕН ЛИЗИНГ & 1401,0 & 788,0 & 56 \\
\hline Прочие лизинговые компании & 9955,2 & 7118,6 & 72 \\
\hline Итого & 35990,8 & 59167,7 & 164 \\
\hline
\end{tabular}

Примечание. Составлено по: [4]. 
ния транспорта и лизинга оборудования. По сути, лизинг становится проводником государственной политики в сегменте поддержки приоритетных отраслей. Это видно на примере клиентов юга России, где компании, которые не обращались к лизингу последние несколько лет, с готовностью включают его в перечень своих финансовых инструментов.

Драйвером развития автолизинга стала госпрограмма Министерства промышленности и торговли РФ льготного лизинга автомобилей, а также новые целевые программы по дополнительному субсидированию субъектов среднего и малого бизнеса, фермеров и транспортных компаний, которые приобретают отечественные машины: «Российский тягач», «Российский фермер» и «Свое дело».

В целом общероссийский и региональный рост рынка лизинга обусловлен потребностью в модернизации российских производств. В данных условиях лизинговые компании и производители разрабатывают и внедряют различные инструменты для развития лизинговых программ, а государство принимает ряд мер, которые призваны стимулировать обновление основных средств в стране, включая меры по поддержке лизинга.

Несмотря на значительный экономический, технический и экспортный потенциал южных регионов и их роль в экономике России, отсутствие законодательной инициативы и существующие социально-экономические и политические проблемы привели к тому, что лизинговый бизнес в ЮФО и СКФО составил только $7 \%$ от общего объема новых сделок в 2017 году. Структурирование негативных факторов позволяет выделить основные из них: высокие процентные ставки по кредитам; недостаточная платежеспособность потенциальных лизингополучателей; рост валютных курсов и снижение спроса со стороны потенциальных клиентов; недоработки в нормативноправовой базе; недостаток у лизинговых компаний «длинных финансовых ресурсов»; недостаточная информированность лизингополучателей в отношении преимуществ и эффективности лизинговых услуг.

В современных условиях рынку лизинга южных регионов присущи как характерные для всего лизингового рынка риски (фондирования, так как доля банковских кредитов в источниках финансирования лизинговых компаний достаточно велика, а возможность привлечения кредитов и ставки - под вопросом; риски просроченной дебиторской задолженности; риски сокращения программ субсидирования лизинга; риски отсутствия эффективного регулирования и надзора), так и специфические риски, связанные с особенностями региональной экономики, инвестиционным потенциалом регионов и повышенным инвестиционным риском.

Таким образом, можно определить следующие драйверы роста лизингового рынка южных регионов:

- лизинг сельскохозяйственной техники и оборудования, разработка отраслевых решений для АПК;

- автолизинг;

- оперативный лизинг;

- лизинг для среднего и малого бизнеса;

- лизинг для физических лиц;

- финансовый супермаркет, который сегодня выступает перспективной и инновационной формой развития, основной его целью является обеспечение клиентов комплексом финансовых продуктов, включающих взаимосвязанные аналитические, финансовые и консалтинговые услуги, а также услуги по страхованию, банковскому кредитованию и лизингу.

В сегменте среднего и малого бизнеса возможными точками роста объемов продаж лизинговых компаний могут стать: автоматизация и оптимизация бизнес-процесса от поиска клиентов до подписания договора; проведение специальных акций совместно с поставщиками и установление льготных условий по сделкам; развитие дополнительных сервисов; внедрение систем по ведению клиентской базы; активизация маркетинговой работы и выстраивание стратегии привлечения клиентов.

В сегменте крупного бизнеса целесообразно сосредоточиться на следующих направлениях возможного роста объемов продаж: автоматизация и оптимизация бизнес-процесса от поиска клиента до подписания договора; предоставление полнофункционального лизинга; разработка продуктовых решений для отдельных отраслей и отраслевых решений; развитие компетенций сотрудников, направленных на отраслевые и специфические потреб- 
ности клиентов; разработка и реализация удаленных сервисов.

Для кредитных организаций развитие лизинговых услуг в продуктовой линейке будет служить снижению рисков и диверсификации совокупного портфеля, а также содействию в активизации инвестиционного спроса в сегменте крупного бизнеса.

Факторами поддержки рынка лизинга будут являться: общеэкономический рост, повышение надежности и прозрачности лизингового рынка, планомерное снижение ключевой ставки ЦБ, снижение инфляции, сохранение инвестиционной активности в секторе государственных проектов, рост импортозамещения, Но, независимо от проводимых реформ, будущее лизинга за интеграцией с другими финансовыми услугами, развитием совместных программ с производителями предметов лизинга, в том числе автопроизводителями, и повышением стандартов клиентского сервиса [5].

Основные меры поддержки: законодательное разрешение передачи в лизинг программного обеспечения в составе оборудования; создание системы страхования коммерческих рисков в лизинговых сделках; законодательное закрепление безусловного права изъятия объекта лизинга без судебных процедур; повышение прозрачности деятельности лизинговых компаний как участников финансового рынка, сотрудничество с рейтинговыми агентствами и организациями мониторинга; разработка нормативной базы по регулированию вопросов государственной регистрации договоров лизинга недвижимости; разрешение пробелов в законодательстве: разработка мобильных программ по расчету графиков лизинговых платежей - лизинговых калькуляторов и автоматизация лизинговой деятельности.

Таким образом, успех российского лизинга зависит от общего экономического роста и инвестиционной активности, создания прозрачной и непротиворечивой нормативной базы, мер государственной поддержки и реализации инфраструктурных проектов. При этом наиболее успешными станут сегменты, где господдержка достигнет максимальных значений, такие как автотранспорт и сельское хозяйство. В настоящее время в рамках укреп- ления надежности финансовой системы ЦБ РФ и Минфин разработали ряд мер по регулированию лизингового рынка. При условии сохранения государственной поддержки и выполнении мер по увеличению надежности и прозрачности (в ситуации недостаточности собственных средств у большинства компаний среднего и малого бизнеса на техническое перевооружение или модернизацию) рынок лизинговых услуг сможет показать высокие темпы роста и поддерживать инновационную траекторию экономического роста.

Сегодня лизинговое финансирование является востребованным источником развития бизнеса для таких инфраструктурных отраслей, как сельское хозяйство, транспорт, связь, энергетика, строительство. Российский рынок лизинговых услуг сегодня не насыщен и, при поддержке определенных факторов, имеет высокий потенциал роста. Снижение удорожания и эффективных ставок, возможности включения страховых сумм в лизинговые платежи и предоставления сезонного или гибкого графика платежей, уменьшение минимального размера авансового платежа, расширение спектра предоставляемых услуг предопределили повышение доступности лизинговых схем в последние годы.

В современных условиях лизинг является одним из существенных факторов инновационно-технологического развития предприятий, перспективным инструментом их инвестиционной и финансовой поддержки. Он способствует ускоренной модернизации основных фондов, обновлению производственного оборудования, созданию и внедрению новых технологий. Стратегические задачи в области промышленного импортозамещения и высокотехнологичных отраслей повышают роль лизинга и определяют спрос на лизинговые услуги. Данная форма финансирования должна быть основана на реализации федеральных и региональных программ, взаимодействии государства и бизнеса, а также направлена на формирование условий создания необходимой инфраструктуры для рынка инжиниринга, обеспечение его конкурентных преимуществ и развитие инновационной экономики России.

Проведенная оценка тенденций развития лизингового рынка южных регионов показала, что для него характерны как общие для 
лизингового рынка риски и пути развития, так и специфические, связанные в первую очередь с особенностями региональной экономики, инвестиционным потенциалом регионов и повышенным инвестиционным риском в СКФО.

В заключение необходимо отметить, что южные регионы имеют огромный потенциал, значительно превосходящий сложившиеся масштабы лизинговых операций. Существует объективная необходимость активизации и использования всех имеющихся возможностей лизинга как эффективного инструмента финансирования развития экономики региона. Развитие лизингового рынка в южных регионах, как и в целом в России, имеет большие перспективы при определенных условиях. Это обусловлено как объективной потребностью в обновлении производственной базы и дефицитом собственных источников финансирования предприятий реального сектора экономики, так и более высокими требованиями и ставками кредитного финансирования. Поэтому лизинг сегодня может стать актуальным инструментом финансирования инвестиций, основой преодоления «инвестиционного голода» и обеспечения устойчивого экономического роста и развития южных регионов.

\section{СПИСОК ЛИТЕРАТУРЫ}

1. Белкин, С. С. Анализ современного состояния лизингового рынка в Российской Федерации / С. С. Белкин // Научно-методический электронный журнал «Концепт». - Электрон. текстовые дан. - Режим доступа: http://e-koncept.ru/2017/ 770308.htm. - Загл. с экрана.

2. Берегатнова, Е. В. Рынок лизинга в РФ: состояние, перспективы / Е. В. Берегатнова. Электрон. текстовые дан. - Режим доступа: https://dcenter.hse.ru/data/2017/01/13/1115379811/ Рынок лизинга РФ 2016.pdf. - Загл. с экрана.

3. Инвестиционный климат регионов -2017 / Рейтинговое агентство «Эксперт». - Электрон. текстовые дан. - Режим доступа: https://raexpert.ru/ ratings/regions/2017. - Загл. с экрана.

4. Рынок лизинга по итогам 2017 года: движение вверх / Рейтинговое агентство «Эксперт». Электрон. текстовые дан. - Режим доступа: https:// raexpert.ru/researches/leasing/2017. - Загл. с экрана.

5. Савицкая, А. Лизинг растет на инфраструктуре / А. Савицкая. - Электрон. текстовые дан. Режим доступа: https://www.kommersant.ru/doc/ 3420267. - Загл. с экрана.

6. Южный Федеральный округ: его состав и значимость. - Электрон. текстовые дан. - Режим доступа: http://fb.ru/article/282794/yujnyiy-federalnyiyokrug-ego-sostav-i-znachimost. - Загл. с экрана.

\section{REFERENCES}

1. Belkin S.S. Analiz sovremennogo sostoyaniya lizingovogo rynka v Rossiyskoy Federatsii [Analysis of the Current State of the Leasing Market in the Russian Federation]. Nauchnometodicheskiy elektronnyy zhurnal «Kontsept». URL: http://e-koncept.ru/2017/770308.htm.

2. Beregatnova E.V. Rynok lizinga $v R F$ : sostoyanie, perspektivy [The Leasing Market in Russia: Condition and Prospects]. URL: https:// dcenter.hse.ru/data/2017/01/13/1115379811/Рынок лизинга РФ 2016.pdf.

3. Investitsionnyy klimat regionov - 2017 [Investment Climate in the Regions - 2017]. Reytingovoe agentstvo «Ekspert» ['Expert' Rating Agency]. URL: https://raexpert.ru/ratings/regions/ 2017.

4. Rynok lizinga po itogam 2017 goda: dvizhenie vverkh [The Leasing Market by the End of 2017: Move up]. Reytingovoe agentstvo «Ekspert» ['Expert' Rating Agency]. URL: https://raexpert.ru/ researches/leasing/2017.

5. Savitskaya A. Lizing rastet na infrastrukture [Leasing Grows on Infrastructure]. URL: https:// www.kommersant.ru/doc/3420267.

6. Yuzhnyy Federalnyy okrug: ego sostav $i$ znachimost [The Southern Federal District: Its Composition and Significance]. URL: http://fb.ru/ article/282794/yujnyiy-federalnyiy-okrug-ego-sostavi-znachimost. 


\section{Information about the Authors}

Emma V. Kuzmina, Candidate of Sciences (Economics), Associate Professor of Department of Theory of Finance, Credit and Taxation, Volgograd State University, Prosp. Universitetsky, 100, 400062 Volgograd, Russian Federation, kuzminaev@volsu.ru, https://orcid.org/0000-0002-8204-4212

Elina S. Kuzmina, Master Student, Volgograd State University, Prosp. Universitetsky, 100, 400062 Volgograd, Russian Federation, elyakuza@mail.ru, https://orcid.org/0000-0003-0386-8553

\section{Информация об авторах}

Эмма Вячеславовна Кузьмина, кандидат экономических наук, доцент кафедры теории финансов, кредита и налогообложения, Волгоградский государственный университет, просп. Университетский, 100, 400062 г. Волгоград, Российская Федерация, kuzminaev@volsu.ru, https://orcid.org/ 0000-0002-8204-4212

Элина Сергеевна Кузьмина, магистрант, Волгоградский государственный университет, просп. Университетский, 100, 400062 г. Волгоград, Российская Федерация, elyakuza@mail.ru, https://orcid.org/0000-0003-0386-8553 